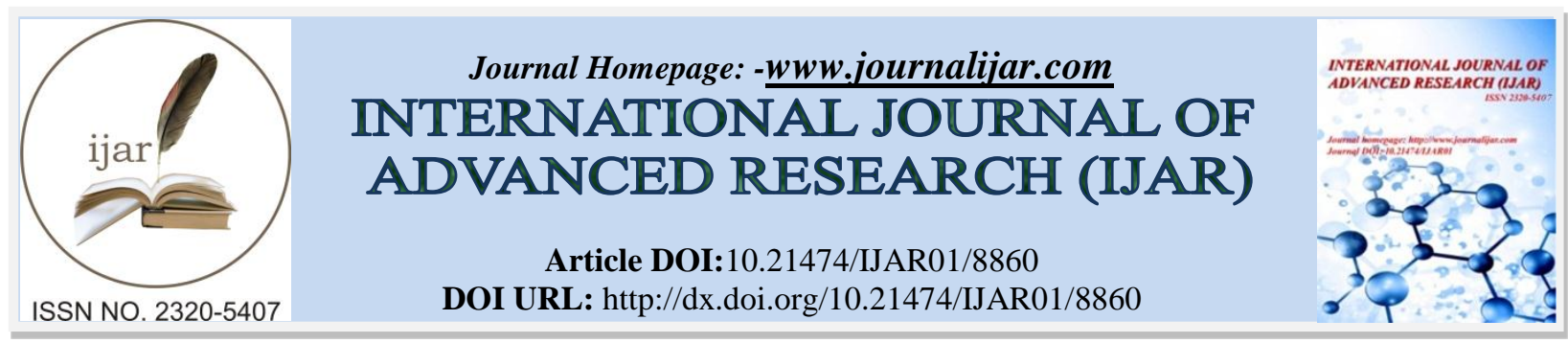

RESEARCH ARTICLE

\title{
EFFECT OF ASTHANGA YOGA ON DEPRESSION FOR MALE INMATES IN PRISON- SHORT COMMUNICATION.
}

Deepika.K, Prabavathy S and Dr. Renuka K.

Department of Mental Health Nursing, Kasturba Gandhi Nursing College, Sri Balaji Vidyapeeth, Puducherry.

\section{Manuscript Info}

Manuscript History

Received: 10 February 2019

Final Accepted: 12 March 2019

Published: April 2019

Key words:-

Prison, Prisoners, Depression, Ashtanga Yoga.

\section{Abstract}

Depressive symptoms are common mental disorders around worldwide. Moreover, the prison environment characterized by overcrowding, stereotype regimen, lack of recreational activities, and high level of uncertainty could lead to depression than in general population Yoga and its various techniques are useful in minimizing the psychological distress like depression of the individuals especially the prisoners. Studies were shown that Yoga and meditation had a good impact on stress management of Female Prisoners.

The present study reported from the data obtained from the Male Inmates by means of semi- structured questionnaire and standard tool shows that selected limbs of Ashtanga Yoga (Asana and Pranayama) are effective in treatment of depression for male Inmates who are convicted for several years.

Copy Right, IJAR, 2019,. All rights reserved.

\section{Introduction:-}

Prison is a place where the inmates are compelled to stay for many years and sometimes for life long to punish them for their mistakes such as committed grave crimes (murder, sexual assaults, robbery). ${ }^{1}$ Depressive symptoms are common mental disorders around worldwide. The prevalence of depression is much higher irrespective of all age groups especially females, old age person, singles and separated person. ${ }^{2}$ The factors that cause depression in prisoners due to illegal activities restricted and prolonged stay, missing of loved ones, living with violent behavior. ${ }^{3}$ "A crime is a way to satisfy a craving, by which it goes beyond normal and by means of legal. Crime, illegal activities and the different anti-social behavior which makes them to express tensions which arise from a deeply dissatisfied mind, from a weak mind and from imbalanced emotional expressions. ${ }^{4,5}$ Ministry of Justice and Family Welfare estimated that around $49 \%$ of women and $23 \%$ of male prisoners have depression and anxiety.

\section{Role Of Yoga On Depression Among Prisoners}

When dealing with inmates it is essential to be make sure that it is important for the person who done the crime/crimes due to inner stress, mental disturbance and unable to cope with stressful situation of the person, When there is imbalance in the relationship between the both the nervous systems (sympathetic and parasympathetic) and imbalance in distribution of hormones in the body, then any sort of deviations in ones behavior can occur. Depending on whether an individual attitude in olden days (i.e tamasic, sattwic, rajasic) in their nature. The balance between the hormones such as adrenaline, nor-adrenaline and acetylcholine varies from one individual to another. There is a great role in the control of, or action of one's physical, emotional and mental activities. The inmates have to practice various ways of dealing with the new environment (Prison) and the other inmates also share among them,

Corresponding Author:-Deepika.K.

Address:-Department of Mental Health Nursing, Kasturba Gandhi Nursing College, Sri Balaji

Vidyapeeth, Puducherry. 
for improving their coping and surviving in the outer environment. The most important way to reduce stress among prisoners is that of practicing yoga in regular basis. ${ }^{8}$

Yoga is one of the alternatives medicines, which is non-invasive, safe, as well as cost-effective. It is well known and proved scientifically that the hormones such as adrenaline, nor- adrenaline and acetylcholine can be maintained and regulated through regular practice of yoga. ${ }^{9}$ Yogic practices maintains the physical and emotional stability of an individual. The person who is committing will have an unstable mind and thoughts that leads to the expression of negative physical symptoms. A weak mind always has an imbalance in sense of proportion. Unless the basic weakness of mind is repaired by means of Yoga, misconduct of an individual is truly ineffective. ${ }^{10}$

Yoga and its various techniques like Asana and Pranayama (relaxation, meditation, relaxation, and concentration) can be useful to minimize the psychological distress like depression of the individuals especially the prisoners. Thus, there is a high need for staying fit and healthy during their stay in prison.

\section{Conclusion:-}

As a researcher I have made a Practice of Yoga technique (Tala Asana, Veera Asana, Bhujangasana, Pavanamukthasana, Bhrama Mudra, Pranava Pranayama, Shavasana with Marmanasthana Kriya) are a powerful tool to keep prisoners healthy and to have good psycho- physical condition by proved that the 21 days for 30 minutes of yoga practice makes an inmates to have a decreased level of depressive symptoms and the confident level gets improved, maintained a good relationship with their inmates when compared to before practice of yoga session.

Hence I suggest that yoga can be a part of their daily routine which makes them to stay fit while they are in a prison environment.

This study proved that this technique is statistically significant to practice in their day to day life.

\section{References:-}

1. Pandey, R. and Kalra, A. (2003): Root knot disease of ashwagandha Withania somnifera and its ecofriendly cost effective management. J. Mycol. Pl. Pathol., 33(2): 240-245.

2. Roth and Michael P (2006): Prisons and Prison System. A Global Encyclopedia. Greenwood Publishing. 201605-15 Available from: URL: https://www.maria-online.us/health/article.php?lg=en\&q=Prison

3. Butler T, Allnutt S, Cain D, Owens D, Muller C (2005) : Mental disorder in the New South Wales prisoner population. J Psychiatry, 39 (5):407- 413.

4. Castellano T. C. and Soderstrom I. R. (1997): Self Esteem, Depression, and Anxiety Evidenced by a Prison Inmate Sample: Interrelationships and Consequences for Prison Progamming. The Prison Journal, 77 (3): 259 280 .

5. Walmsley R. (2013) World prison population list. International Center for Prison Studies, 10 (3): $12-15$

6. Ligi Thomas (2018). Screening or depression among Inmates. Indian Journal of Psychiatry. 2010: (4): 52 (2): $150-123$

7. Journal of Psychiatric medicine (2015): 5 (4): 128-130.

8. World Health Organization, WHO. 2007. Health in prisons: A WHO guide to the essentials in prison health. Copenhagen: Organization Regional Office for Europe. [Accessed: 2017 April 21].

9. Woolery A, Myers H, Sternlieb B, Zeltzer L. (2004) A yoga intervention for young adults with elevated symptoms of depression. Alternate Health Med.;10:60-3

10. Bhushan, Dr L.I. Yoga: An Instrument of Psychological Trans-formation, Yoga, September 1998, Sivananda Math, Munger.

11. Abhishek K Baradhwaj (2013) : An interventional study on effect of yoga practice on self esteem : J of Yoga, Dec;13 54-62 